\title{
Sensory specific satiety is impervious to the tasting of other foods with its assessment
}

Citation for published version (APA):

Havermans, R. C., Siep, N., \& Jansen, A. T. M. (2010). Sensory specific satiety is impervious to the tasting of other foods with its assessment. Appetite, 55, 196-200.

https://doi.org/10.1016/j.appet.2010.05.088

Document status and date:

Published: 01/01/2010

DOI:

10.1016/j.appet.2010.05.088

Document Version:

Publisher's PDF, also known as Version of record

Document license:

Taverne

Please check the document version of this publication:

- A submitted manuscript is the version of the article upon submission and before peer-review. There can be important differences between the submitted version and the official published version of record.

People interested in the research are advised to contact the author for the final version of the publication, or visit the DOI to the publisher's website.

- The final author version and the galley proof are versions of the publication after peer review.

- The final published version features the final layout of the paper including the volume, issue and page numbers.

Link to publication

\footnotetext{
General rights rights.

- You may freely distribute the URL identifying the publication in the public portal. please follow below link for the End User Agreement:

www.umlib.nl/taverne-license

Take down policy

If you believe that this document breaches copyright please contact us at:

repository@maastrichtuniversity.nl

providing details and we will investigate your claim.
}

Copyright and moral rights for the publications made accessible in the public portal are retained by the authors and/or other copyright owners and it is a condition of accessing publications that users recognise and abide by the legal requirements associated with these

- Users may download and print one copy of any publication from the public portal for the purpose of private study or research.

- You may not further distribute the material or use it for any profit-making activity or commercial gain

If the publication is distributed under the terms of Article $25 \mathrm{fa}$ of the Dutch Copyright Act, indicated by the "Taverne" license above, 
Research report

\title{
Sensory-specific satiety is impervious to the tasting of other foods with its assessment ${ }^{\text {is }}$
}

\author{
Remco C. Havermans *, Nicolette Siep, Anita Jansen \\ Maastricht University, Faculty of Psychology E Neuroscience, Clinical Psychological Science, PO Box 616, 6200 MD Maastricht, The Netherlands
}

\section{A R T I C L E I N F O}

\section{Article history:}

Received 16 December 2009

Received in revised form 20 May 2010

Accepted 21 May 2010

\section{Keywords:}

Habituation

Neural adaptation

Sensory-specific satiety

\begin{abstract}
A B S T R A C T
Sensory-specific satiety (SSS) refers to the reduction in pleasantness of a food with its consumption relative to other unconsumed foods. In a typical SSS paradigm, the participants receive a range of food items to taste and evaluate and then one of the foods is consumed ad libitum until satiation. After the consumption of the test food, all the foods (including the test food) are then again tasted and evaluated. If SSS is the result of habituation this evaluation of the test food after its consumption would be subject to dishabituation (i.e. recovery of SSS) if the other unconsumed foods are evaluated first. To examine whether this is the case a total of 57 participants were randomly assigned to one of two groups: Test Food First (TFF; $n=28$ ) or Test Food Last (TFL; $n=29$ ). We hypothesized that group TFF would show stronger SSS than TFL. We found clear indication of SSS, but the degree of SSS did not differ between the two groups $(F[1,55]<1)$. This finding suggests that SSS is unaffected by the sequence of tasting food items with its assessment. The potential implications for understanding SSS in terms of habituation are discussed.
\end{abstract}

(c) 2010 Elsevier Ltd. All rights reserved.

\section{Introduction}

Sensory-specific satiety (henceforth SSS) refers to a decrease in pleasantness of a food with the consumption of that food, relative to other unconsumed foods. In a typical SSS experiment participants first receive a pre-test that comprises tasting and evaluating the pleasantness of different sensory characteristics of a range of different food items. Next, the participants are instructed to eat one of the foods (the test food) until satiation, after which there is a post-test similar to the pre-test. At this post-test, the test food is usually less liked than at pre-test, whereas there is little (if any) change in pleasantness for the other unconsumed foods (the control foods) (Hetherington \& Rolls, 1996; Rolls, 1986).

One mechanism generally thought to underlie SSS is response habituation. Indeed, Epstein, Temple, Roemmich, and Bouton (2009) recently noted that in the context of food consumption the two terms are often used interchangeably. There is much to be said for describing SSS in terms of habituation. Response habituation refers to the decrease in responsiveness to a particular stimulus with

\footnotetext{
The authors would like to acknowledge the help from students Renée Lippinkhof, Mia Schuermans, Saskia Wolff, Rodrigo Cardoso Costa, Antonis Antopoulos, and Jolien de Wolf. The authors would further like to thank an anonymous reviewer for inspiring the present study.

* Corresponding author.

E-mail address: r.havermans@maastrichtuniversity.nl (R.C. Havermans).
}

repeated or prolonged stimulation. For example, a loud noise will elicit a startle response but with repeated presentations of the noise this startle response habituates (Davis \& Wagner, 1968; Vogel \& Wagner, 2005). The primary response system involved in SSS is hedonic, that is, momentary pleasantness of the sensory characteristics of a food or drink. Such experienced pleasantness is reduced with continuous or repeated orosensory exposure to that particular food or drink (see e.g. Havermans, Geschwind, Filla, Nederkoorn, \& Jansen, 2009; Havermans, Janssen, Giesen, Roefs, \& Jansen, 2009).

Habituation is sometimes referred to as single stimulus learning, the learning that a particular potentially dangerous stimulus is in fact harmless and can be ignored. Note that this differs from the function usually ascribed to SSS, namely that SSS serves to promote eating a more varied meal (Hetherington \& Rolls, 1996). To conclude that any reduction in behavior with repeated stimulation is the result of learning, however, requires the refutation of several alternative explanations, such as sensory adaptation and fatigue. One may stop responding to a loud noise if one can no longer adequately hear the noise, and one stops responding to the noise if one is simply too tired to respond. To rule out these alternative explanations for response habituation, one has to demonstrate the immediate recovery of the habituated response, or dishabituation. If stimulation is changed or continued in a different environmental setting habituated responding will show at least partial recovery (Marlin \& Miller, 1981; Vogel \& Wagner, 2005); that is, the change in stimulation serves to restore responding to the original habituating stimulus (Epstein et al., 2009). 
If SSS can be ascribed to a habituation process, one would expect that a food change would attenuate SSS, indicative of dishabituation. There are several studies that appear to demonstrate precisely such an effect. Wisniewski, Epstein, and Caggiula (1992) found that participants after eating a palatable food until satiation showed stronger salivary responding, relatively increased consumption and stronger liking for a second serving if that serving was another food. Recently, Hetherington, Foster, Newman, Anderson, and Norton (2006) demonstrated in a series of two experiments that the expected decline in pleasantness ratings with the consumption of a test food is attenuated when participants regularly had to taste a different food during the consumption of the test food (see also Brunstrom \& Mitchell, 2006). This too suggests that SSS can dishabituate and that, as such, a decrease in hedonic ratings of a test food during consumption can be ascribed to response habituation.

Recently, Brondel, Lauraine, Van Wymelbeke, Romer, and Schaal (2009) hypothesized that when presuming that habituation underlies SSS, increasing the number of alternations between foods in a meal should increase intake by undermining habituation. They found that repeated alternating consumption of two different foods affects the ad libitum consumption of one of these foods at the end of a meal. With a single repetition, food intake at test was augmented as compared to a condition involving no repetitions, suggesting that food change undermines SSS. However, in the case of multiple repeated alternations, consumption of the test food decreased. Brondel and colleagues speculate that this is perhaps because multiple repetitions of alternated consumption of foods comprise a more intense exposure to food cues. In line with this reasoning Weijzen, Smeets, and de Graaf (2009) demonstrated that the extent of orosensory exposure to orangeade determines sensory satiation for the drink, with more exposure promoting satiation. Alternations between foods interrupt exposure to the specific sensory experience of any of these foods and hence retard the development of SSS. However, with many alternations the overall exposure to the test food may be more than enough to induce strong SSS for it. According to this explanation, a food change does not necessarily disrupt or dishabituate SSS. If SSS for a test food is allowed to develop then a sudden food change should not be able to alleviate this SSS, meaning that SSS cannot be equated with response habituation.

In discussing to what extent food habituation and sensoryspecific satiety refer to the same underlying process, Epstein and colleagues (2009, p. 400) noted the following: "If the first food that is tested after repeated food consumption is the same food that was consumed, it is possible to show habituation, and if the subsequent food is a different food, then stimulus specificity of responding is similar to habituation paradigms." Therefore, to test to what degree a habituation procedure and a typical SSS paradigm match up, we examined whether SSS is less pronounced when at post-test the test food is evaluated after the tasting of the other control food items. If SSS is a form of habituation the intermediate tasting of the control food items should (at least to some extent) dishabituate the decreased hedonic ratings of the test food. In other words, SSS should be less pronounced when at post-test one is required to taste and rate the test food after the control food items.

\section{Methods}

\section{Participants}

A total of 57 undergraduate psychology students from Maastricht University took part in the present study. They were randomly assigned to one of two groups: Test Food First (TFF; $n=28$ ) or Test Food Last (TFL; $n=29$ ). Participant characteristics are displayed in Table 1.

\section{Procedure, materials and design}

The present experiment was approved by a local ethical committee. Participants took part to fulfil course requirements and were tested individually during weekdays between noon and 5 PM. Participants were instructed beforehand to eat something small (e.g., a single sandwich or bread roll) exactly two hours prior to their participation in the experiment, and henceforth to refrain from drinking and eating anything (including drinking water and chewing gum) until the experiment.

Upon arrival, the participant was seated at a table and was provided with both written and oral information regarding the experiment. The experimental procedure (but not the experimental design and hypothesis) was disclosed and after returning a signed consent form, the participant received four bite size portions of different food items: milk chocolate $(530 \mathrm{kcal} / 100 \mathrm{~g}$; Milka, Kraftfoods The Netherlands) cheese cracker (525 kcal/100 g; TUC, LU General Biscuits, The Netherlands), fruit yoghurt (65 kcal/ $100 \mathrm{ml}$; Albert Heijn, the Netherlands) and potato chips (544 kcal/ $100 \mathrm{~g}$; Lay's, PepsiCo US). The participant was instructed to consume each food and rate momentary pleasantness of taste and smell on 100-mm line scales ranging from 0 "very disliked" (left anchor) to 100 "very liked" (right anchor). Further, the participant was asked to indicate for each food item how much he would like eating more of it on another 100-mm line scale ranging from 0 "not at all" to 100 "very much". This evaluation had a 3 min duration.

After evaluating the different foods, the participant received a $500 \mathrm{ml}$ bowl filled with one of the four foods and was told to consume this test food until pleasantly full. Participants were free to ask for refills. Which of the four foods served as the test food was randomly determined per participant. The amount consumed was determined by weighing the bowl of food before and after

Table 1

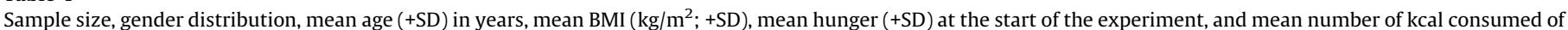
the test food (+SD) for each separate group (Test Food First [TFF] vs. Test Food Last [TFL]).

\begin{tabular}{|c|c|c|c|}
\hline & \multicolumn{3}{|l|}{ Group } \\
\hline & TFF & TFL & \\
\hline$N$ & 28 & 29 & \\
\hline \multicolumn{4}{|l|}{ Gender } \\
\hline$N$ male & 10 & 12 & $\chi^{2}=.19, p=.61$ \\
\hline$N$ female & 18 & 17 & \\
\hline Mean age (yrs) & $22.5(4.6)$ & $22.6(5.9)$ & $t(55 d f)=.01, p=.99$ \\
\hline Mean BMI $\left(\mathrm{kg} / \mathrm{m}^{2}\right)$ & $23.48(2.85)$ & $22.33(2.65)$ & $t(55 d f)=1.58, p=.12$ \\
\hline Mean hunger $(0-100)$ & $45.11(24.87)$ & $48.86(24.91)$ & $t(55 d f)=.57, p=.57$ \\
\hline Mean number of kcal consumed & $164.43(118.08)$ & $189.06(119.36)$ & $t(55 d f)=.78, p=.44$ \\
\hline
\end{tabular}

Note: Tests for differences in gender distribution, age, BMI, hunger and caloric consumption between TFF and TFL are displayed in the last column. 
Table 2

Experimental design of the present study.

\begin{tabular}{|c|c|c|c|c|}
\hline & \multicolumn{4}{|l|}{ Phase } \\
\hline & Pre-test & Consumption & Post-test (a) & Post-test (b) \\
\hline \multicolumn{5}{|l|}{ Group } \\
\hline TFF & Evaluation of control foods and test food & Ad libitum consumption of test food & Evaluation of test food & Evaluation of control foods \\
\hline TFL & Evaluation of control foods and test food & Ad libitum consumption of test food & Evaluation of control foods & Evaluation of test food \\
\hline
\end{tabular}

Note: TFF and TFL refer to the groups Test Food First and Test Food Last respectively, with "first" referring to post-test (a) and "last" referring to post-test (b).

consumption of the test food on a scale capable of accurately weighing milligrams (Mettler Toledo, Tiel, The Netherlands). This consumption of the test food had a maximal duration of $10 \mathrm{~min}$, meaning that even when not experiencing satiation after $10 \mathrm{~min}$ of eating the test food, the participant would have to proceed with the re-evaluation of the four different food items. All participants however, indicated satiation before the $10 \mathrm{~min}$ time limit. Directly after consuming the test food until satiation, the participant received a second taste test in which he was instructed to taste and evaluate pleasantness of taste and smell, and how much he would like to eat of bite-sized portions of each of the four food items. However, this second taste test differed slightly from the first taste test in the sense that now the four food items were presented serially, meaning that the participants could not taste and evaluate the foods in whatever order they chose. Participants in group TFF received the test food as the first food to taste and evaluate, whereas participants from group TFL received the test food as the last food to evaluate.

After the second taste test, the participant's body weight and length was measured to assess body mass index (BMI; $\mathrm{kg} / \mathrm{m}^{2}$ ). The experimental design is displayed in Table 2.

\section{Data analysis}

To be able to determine the reduction of pleasantness for the test food relative to the control foods we first calculated the average rating scores for the control foods concerning the taste ratings, smell ratings and ratings of how much one would like to eat the food. To examine the hypothesis that the degree of SSS differs depending on when the test food was evaluated at the second taste test (first vs. last), we then conducted separate Test (1 vs. 2$) \times$ Food (test food vs. control foods) $\times$ Group (TFF vs. TFL) ANOVAs for each dependent variable (taste rating, smell rating, and how much one would like to eat the food). All analyses were conducted with SPSS 15.0 for Windows.

\section{Results}

As displayed in Table 1, we found no differences between the two groups in the degree of food intake (i.e. caloric consumption) when comparing TFF with TFL on the number of calories consumed during the ad libitum consumption phase of the experiment.

The mean ratings of taste, smell and the motivation to eat for the test food and the control foods before and after the consumption of the test food for each separate group (TFF and TFL) are displayed in Fig. 1. For ratings of taste, main effects were found for Test $\left(F[1,55]=41.33, p<.001, \eta_{\text {partial }}^{2}=.43\right)$ and for Food $\left(F[1,55]=4.96, p<.05, \eta_{\text {partial }}^{2}=.08\right)$. These effects were qualified by a significant Test $\times$ Food interaction, $F(1,55)=26.20, p<.001$, $\eta_{\text {partial }}^{2}=.32$, indicative of SSS. The degree of this effect did not differ between the two groups (TFF vs. TFL) given the absence of an overall three-way Test $\times$ Food $\times$ Group interaction, $F(1,55)<1$. No further interactions were found (all Fs $<1$ ).

When considering the smell ratings, again, main effects were found for Test $\left(F[1,55]=16.27, p<.001, \eta_{\text {partial }}^{2}=.23\right)$ and Food
$\left(F[1,55]=4.70, p<.05, \eta_{\text {partial }}^{2}=.08\right)$. Both groups demonstrated clear SSS as evidenced by a Test $\times$ Food interaction for smell, $F(1$, $55)=10.95, p=.002, \eta_{\text {partial }}^{2}=.17$, but similar to the taste ratings no three-way interaction was found $(F[1,55]<1)$, implying that SSS for the smell ratings too did not differ between groups. Neither Test nor Food interacted with Group, largest $F(1,55)=1.39$.

The ratings for the motivation to eat revealed a similar pattern of results, again showing main effects for Test $(F[1,55]=83.92$, $\left.p<.001, \quad \eta_{\text {partial }}^{2}=.60\right)$ and Food $(F[1,55]=17.85, \quad p<.001$,

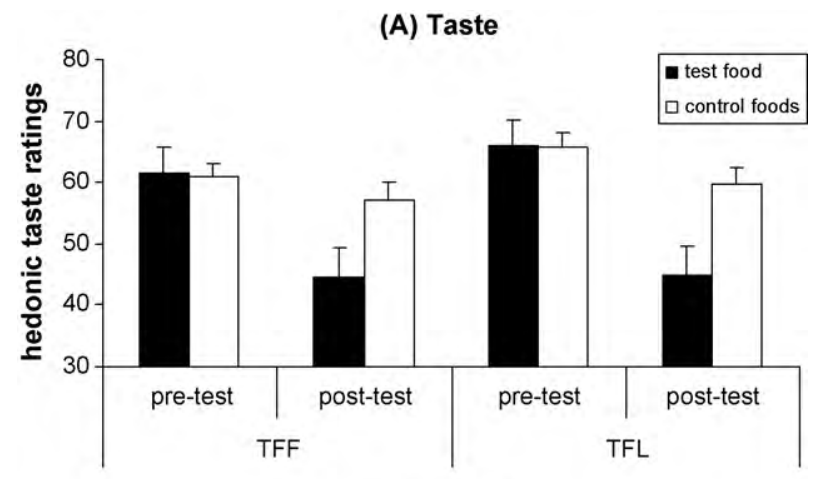

(B) Smell

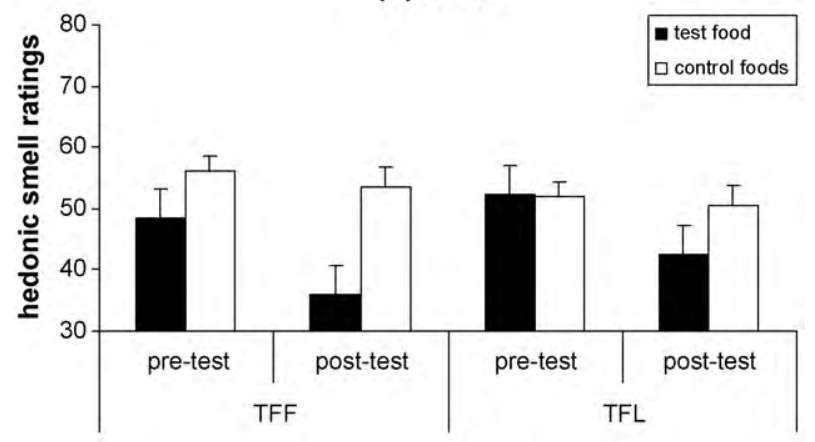

(C) Motivation to eat

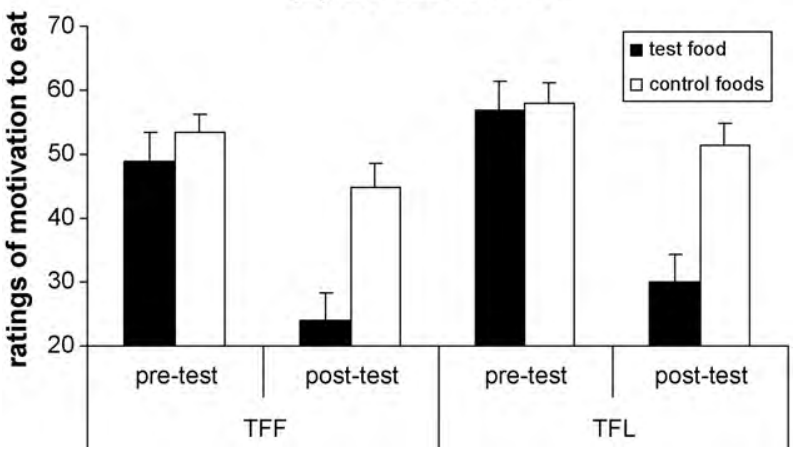

Fig. 1. Mean hedonic ratings (+SEM) of taste (panel A) and smell (panel B), and ratings of the motivation to eat (panel $C$ ) the test food and control foods for each separate group (TFF vs. TFL). 
$\left.\eta_{\text {partial }}^{2}=.25\right), \quad$ qualified by a Test $\times$ Food interaction, $F(1$, $55)=71.46, p<.001, \eta_{\text {partial }}^{2}=.57$, indicating SSS. This SSS did not differ between the two groups as evidenced by the absence of significant Test $\times$ Food $\times$ Group interaction, $F(1,55)<1$.No further interactions were found, all Fs $<1$.

\section{Discussion}

In the present study, we examined whether SSS to a test food is sensitive to a brief interruption of having to taste other flavours. We hypothesized that in this case SSS to the test food would be attenuated, or rather dishabituated. However, we did not find any indication for such dishabituated SSS. Whether the test food was presented directly after the ad libitum consumption phase or only after the in-between evaluation of the control foods, clear SSS was found regardless. This then suggests that SSS is not simply a form of response habituation. Note that this conclusion appears contrary to earlier research findings. For example, Romer et al. (2006) speculated that in Experiment 2 of their study an observed recovery of olfactory pleasure regarding a first food eaten to satiation was due to the consumption of a second, new food, suggestive of dishabituated SSS. However, recovery was far from complete and took approximately $20 \mathrm{~min}$. Furthermore, Romer and colleagues did not include a control group that did ingest the first test food until satiation but not a second test food. Therefore, they cannot resolve whether the observed recovery of olfactory pleasure for the first test food should be ascribed to dishabituation or rather to spontaneous recovery.

As noted in the Introduction, the main response in SSS is a hedonic or affective response. The hedonic or affective response to a test food does not necessarily diminish with an SSS procedure. In fact, in several participants we observed that continuous or repeated exposure to a test food leads to a negative affective response towards this food. In other words, some participants clearly came to dislike the test food. If SSS would involve some form of affective habituation then one would expect to see that both initially liked flavours and disliked flavours become more neutral with its consumption (see Dijksterhuis \& Smith, 2002). This appears to hold true for monotony effects where highly liked but not disliked foods become less liked with its repeated consumption over a longer period of time (e.g., Zandstra, De Graaf, Mela, \& van Staveren, 2000). It does not correspond with SSS for which initial experienced pleasantness for food does not affect sensory satiation with repeated consumption. Indeed, clear SSS has also been observed with relatively neutral flavours such as water (Rolls, Rolls, \& Rowe, 1983). This observation including the present finding that a food change does not bring about an immediate recovery from SSS suggests that a habituation process does not underlie SSS.

A food change may retard the development of SSS but does not prevent it from happening and once SSS is established it simply takes time for it to fully dissipate. Therefore, one may speculate that SSS is the result of underlying short-term food specific neural adaptation within the orbitofrontal cortex (OFC) where food reward is thought to be represented and processed (Rolls, 2000, 2005; Siep et al., 2009). Indeed, repeated exposure to a food odour leads to a decrease in the desire to eat that food (e.g., Jansen et al., 2003) and an odour specific decrease in neuronal activity within the OFC (O'Doherty et al., 2000). Although neuronal activity is restored with the introduction of a new food (Rolls, Critchley, Browning, Hernadi, \& Lenard, 1999), we would argue that this does not dishabituate activity in the OFC with re-exposure to the original test food. In other words, reduced food specific neuronal activity with food intake recovers steadily but not immediately with a food change. Hetherington, Rolls, and Burley (1989) have suggested that such spontaneous recovery takes approximately
60 min. Whether SSS can spontaneously recover but not dishabituate requires further research.

In the context of previous findings concerning the effects of meal variety on sensory satiation and consumption (e.g., Brunstrom \& Mitchell, 2006), one might argue that the present study results implicate that meal variety will retard the development of SSS only when such SSS has not been fully induced yet. If so, this would further mean that eating a meal in separate courses served serially would provide as much food variety when these meal courses or components are served all at once, but with less opportunity for overconsumption because a serial presentation of meal components is more conducive to the development of SSS for each separate course. It should be noted though that this is highly speculative and requires further research.

To recapitulate, the present results suggest that SSS does not instantly dishabituate with a food change, hence raising doubts whether habituation provides an adequate account for sensory satiation. Note however, that definitively discarding an habituation account for SSS would require at the very least a replication of the present results. Future studies examining the potential for dishabituation of SSS might include additional control groups in which nothing is eaten in between the two taste tests. Further, it would be interesting to examine whether the consumption of larger amounts of control foods when evaluating SSS (i.e. larger than the bite-sized portions employed in the present study) will disrupt or alter SSS.

\section{References}

Brondel, L., Lauraine, G., Van Wymelbeke, V., Romer, M., \& Schaal, B. (2009). Alternation between foods within a meal: influence on satiation and consumption in humans. Appetite, 53(2), 203-209.

Brunstrom, J. M., \& Mitchell, G. L. (2006). Effects of distraction on the development of satiety. British Journal of Nutrition, 96(4), 761-769.

Davis, M., \& Wagner, A. R. (1968). Startle responsiveness after habituation to different intensities of tone. Psychonomic Science, 12(7), 337-338.

Dijksterhuis, A., \& Smith, P. K. (2002). Affective habituation: subliminal exposure to extreme stimuli decreases their extremity. Emotion, 2(3), 203-214.

Epstein, L. H., Temple, J. L., Roemmich, J. N., \& Bouton, M. E. (2009). Habituation as a determinant of human food intake. Psychological Review, 116(2), 384-407.

Havermans, R. C., Geschwind, N., Filla, S., Nederkoorn, C., \& Jansen, A. (2009). Sensoryspecific satiety is unaffected by manipulations of flavour intensity. Physiology $\mathcal{E}$ Behavior, 97(3-4), 327-333.

Havermans, R. C., Janssen, T., Giesen, J. C. A. H. , Roefs, A., \& Jansen, A. (2009). Food liking, food wanting, and sensory-specific satiety. Appetite, 52(1), 222-225.

Hetherington, M. M., \& Rolls, B. J. (1996). Sensory-specific satiety: theoretical frameworks and central characteristics. In E. D. Capaldi (Ed.), Why we eat what we eat: the psychology of eating (pp. 267-290). Washington, DC, US: American Psychological Association.

Hetherington, M., Rolls, B. J., \& Burley, V. J. (1989). The time course of sensory-specific satiety. Appetite, 12, 57-68.

Hetherington, M. M., Foster, R., Newman, T., Anderson, A. S., \& Norton, G. (2006). Understanding variety: tasting different foods delays satiation. Physiology $\mathcal{E}$ Behavior, 87(2), 263-271.

Jansen, A., Theunissen, N., Slechten, K., Nederkoorn, C., Boon, B., Mulkens, S., et al. (2003). Overweight children overeat after exposure to food cues. Eating Behaviors, 4(2), 197-209.

Marlin, N. A., \& Miller, R. R. (1981). Associations to contextual stimuli as a determinant of long-term habituation. Journal of Experimental Psychology: Animal Behavior Processes, 7(4), 313-333.

O’Doherty, J., Rolls, E. T., Francis, S., Bowtell, R., McGlone, F., Kobal, G., et al. (2000). Sensory-specific satiety-related olfactory activation of the human orbitofrontal cortex. NeuroReport: For Rapid Communication of Neuroscience Research, 11(2), 399403.

Rolls, B. J. (1986). Sensory-specific satiety. Nutrition Review, 44, 93-101.

Rolls, E. T. (2000). The orbitofrontal cortex and reward. Cerebral Cortex, 10(3), 284-294.

Rolls, E. T. (2005). Taste, olfactory, and food texture processing in the brain, and the control of food intake. Physiology E Behavior, 85(1), 45-56.

Rolls, E. T., Rolls, B. J., \& Rowe, E. A. (1983). Sensory-specific satiety and motivationspecific satiety for the sight and taste of food and water in man. Physiology \& Behavior, 30, 185-192.

Rolls, E. T., Critchley, H. D., Browning, A. S., Hernadi, I., \& Lenard, L. (1999). Responses to the sensory properties of fat of neurons in the primate orbitofrontal cortex. Journal of Neuroscience, 19, 1532-1540.

Romer, M., Lehrner, J., Van Wymelbeke, V., Jiang, T., Deecke, L., Brondel, L., et al. (2006). Does modification of olfacto-gustatory stimulation diminish sensory-specific satiety in humans? Physiology \& Behavior, 87(3), 469-477. 
Siep, N., Roefs, A., Roebroeck, A., Havermans, R., Bonte, M. L., \& Jansen, A. (2009). Hunger is the best spice: an fMRI study of the effects of attention, hunger and calorie content on food reward processing in the amygdala and orbitofrontal cortex. Behavioural Brain Research, 198(1), 149-158.

Vogel, E. H., \& Wagner, A. R. (2005). Stimulus specificity in the habituation of the startle response in the rat. Physiology \& Behavior, 86(4), 516-525.
Weijzen, P. L. G., Smeets, P. A. M., \& de Graaf, C. (2009). Sip size of orangeade: effects on intake and sensory-specific satiation. British Journal of Nutrition, 102(7), 1091-1097.

Wisniewski, L., Epstein, L. H., \& Caggiula, A. R. (1992). Effect of food change on consumption, hedonics, and salivation. Physiology E Behavior, 52(1), 21-26.

Zandstra, E. H., De Graaf, C., Mela, D. J., \& van Staveren, W. A. (2000). Short and longterm effects of changes in pleasantness on food intake. Appetite, 34, 253-260. 